\title{
Plantão Psicológico Centrado na Pessoa: Intervenção Etnopsicológica em Terreiro de Umbanda
}

\author{
Fabio Scorsolini-Comin ${ }^{1}$ \\ Departamento de Psicologia da Universidade Federal do Triângulo Mineiro, \\ Uberaba, Minas Gerais, Brasil
}

\begin{abstract}
Resumo
O objetivo deste estudo é apresentar e discutir a implantação de um serviço de plantão psicológico em um terreiro de umbanda no interior do Estado de São Paulo, o contexto dos atendimentos, suas características, demandas, dificuldades e possibilidade de atenção à comunidade. Trata-se de um estudo de caso coletivo por meio de duas vinhetas escritas a partir de registros em diários de campo sobre os plantões, conduzidos por dois psicólogos. A análise foi conduzida a partir da abordagem centrada na pessoa e da literatura sobre etnopsicologia. A postura de alteridade e respeito ao outro possibilita a assunção de um cuidado alinhado com as necessidades da comunidade. O plantão constitui um serviço auxiliar na instituição e tem se apresentado como possibilidade de escuta e acolhimento de conflitos considerando as características do funcionamento do terreiro. Conclui-se que o plantão psicológico não pode ser oferecido com a intenção de se diferenciar do apoio já existente no terreiro, mas como uma prática paralela e integrada ao contexto cultural no qual as pessoas da comunidade estão imersas. Aponta-se para a inovação da proposta no campo do aconselhamento multicultural e espera-se que novas pesquisas deem prosseguimento a esta experiência.
\end{abstract}

Palavras-chave: Plantão psicológico, aconselhamento psicológico, etnopsicologia, umbanda.

\section{Person-Centered Psychological Emergency Attendance: Ethnopsychological Intervention in an Umbanda Terreiro (Backyard)}

\begin{abstract}
This study aims to present and discuss the implementation of psychological service in an Umbanda backyard in a city in the state of São Paulo, Brazil, its their characteristics, demands, difficulties and possibility of attention to community. This paper refers to a study of a collective case through two vignettes registered on a field diary about the attendances. Analysis was conducted based on the person-centered approach and on the ethnopsychological literature. Respectful alterity promotes due care to the necessities of the community. Emergency attendances constitute an auxiliary service in the institution, which allows conflicts to be listened and treated, considering how the Terreiro (backyard) works and its characteristics. It has been concluded that emergency attendance cannot be offered with the intention of differentiating the support already present at the backyard, but as a parallel practice integrated to its cultural context, in which people from the community are immersed. Innovations on the proposal are needed in the field of multicultural counseling and new researches are expected in order to continue this experience.
\end{abstract}

Keywords: Emergency psychological attendance, counseling, ethnopsychology, umbanda.

1 Endereço para correspondência: Departamento de Psicologia, Universidade Federal do Triângulo Mineiro, Avenida Getúlio Guaritá, 159, 3ํandar, Abadia, Uberaba, MG, Brasil 38025-440. E-mail: fabioscorsolini@, gmail.com

Agência de financiamento: Conselho Nacional de Desenvolvimento Científico e Tecnológico (CNPq). 


\section{Orientación Psicológica Centrada en la Persona: Intervención Etnopsicológica en Umbanda}

\section{Resumen}

Este trabajo objetivó presentar y discutir la implantación de un servicio de orientación psicológica en un espacio de expresión religiosa umbandista situado en el interior del estado de São Paulo, Brasil, sobre el contexto de las asistencias, características, demandas, dificultades y posibilidades de atención a la comunidad. Se trata de un estudio de caso colectivo por medio de dos viñetas escritas de registros en diarios de campo sobre las visitas realizadas por dos psicólogos. El análisis se realizó sobre el enfoque centrado en la persona y en la literatura sobre etnopsicología. La actitud de respeto y alteridad entre los demás permite la asunción de un cuidado alineado con las necesidades de la comunidad. La guardia constituye un servicio auxiliar en institución y se presenta como una posibilidad de escuchar y acomodar los conflictos considerando las características del funcionamiento del espacio religioso. Se concluye que la guardia psicológica no puede ser ofrecida con la intención de diferenciarse del apoyo existente en el espacio religioso, pero como una practica paralela y integrada al contexto cultural de la comunidad en la cual las personas hacen parte. Señalase la innovación de la propuesta en el campo de la orientación multicultural y se espera que nuevas investigaciones futuras continúen esta experiencia.

Palabras clave: Guardia psicológica, orientación psicológica, etnopsicología, Umbanda.

"O passado ou o futuro é sempre agora"

(Fernando Pessoa, 1914, citado por Cavalcanti Filho, 2013, p. 169).

O plantão psicológico é uma modalidade de atendimento derivado do aconselhamento psicológico. Sua difusão no Brasil ocorreu na década de 1970 a partir de sua implantação no Serviço de Aconselhamento Psicológico da Universidade de São Paulo. Desde o início desses atendimentos, vistos como possibilidade de inovação, muitas foram as experiências desenvolvidas em diferentes instituições de ensino, pesquisa e atenção à comunidade (Mahfoud, 2013; Rosenberg, 1987). Entre as características de um serviço de plantão psicológico, resguardadas as especificidades de cada modelo e abordagem, podemos destacar: (a) oferta de atendimentos em dias e horários pré-estabelecidos e amplamente divulgados, mantendo frequência e periodicidade nessa oferta de ajuda, sem necessidade de agendamento; (b) a busca pelo atendimento parte da pessoa em situação de sofrimento psíquico, de modo que o pedido de ajuda ocorre no momento em que ela precisa; (c) compreensão de que o plantão pode se constituir com um único atendimento ou em alguns encontros, devendo ser ana- lisado em sua complexidade e na possibilidade de oferecer tanto alívio psicológico emergencial como um processo de bem-estar que se atualiza em apenas uma sessão.

A complexidade do plantão reside justamente no fato de que apenas um encontro pode ser potencializador de mudanças se o mesmo for conduzido de modo a facilitar que a pessoa clarifique a sua demanda e compreenda que é parte central na resolução do seu conflito. Em alguns casos, encaminhamentos podem ser realizados a partir da escuta em plantão, podendo o cliente prosseguir em processo psicoterapêutico, além de indicações de outros tratamentos por diferentes profissionais ou em instituições especializadas (Mahfoud, 2013; Perches \& Cury, 2013). Embora o plantão possa ser considerado como uma porta de entrada para serviços psicológicos, por exemplo, em um serviço-escola, deve ser abordado em suas características específicas e não como uma forma de triagem da demanda em busca de atendimento (Fujisaka et al., 2013). $\mathrm{Na}$ abordagem centrada na pessoa, tal como enlevado neste estudo, essas características se somariam à atitude do plantonista em relação ao cliente, ou seja, de estabelecer ao longo do atendimento a empatia, consideração positiva 
incondicional e a autenticidade, considerados elementos fundamentais para o estabelecimento de uma relação positiva (Tassinari, Cordeiro, \& Durange, 2013).

A produção científica destaca a contemporaneidade e a importância do campo do plantão psicológico como intervenção em situações de urgência e como prática de destaque na formação do psicólogo. Em muitos casos, o plantão é oferecido como um dos primeiros estágios específicos supervisionados na formação dos psicólogos, sendo uma prática de iniciação do aluno no universo clínico. Em alguns relatos, os atendimentos em plantão, notadamente os existentes em serviços-escola de Psicologia das universidades acabam funcionando como porta de entrada de usuários, sendo um primeiro contato da comunidade com o serviço psicológico oferecido (Zanuzzi, Santeiro, \& Scorsolini-Comin, 2014).

Os contextos nos quais é ofertado o plantão são cada vez mais diversificados, como escolas, creches, serviços-escola de Psicologia, Centros de Referência Especializados da Assistência Social, Defensoria Pública, hospitais, centros de tratamento intensivo, instituições de longa permanência para idosos, centros de convivência, igrejas, distritos policiais, entre outros (Kovács, 2010; Lessard, Marchand, \& Lavoie, 2012; Perches \& Cury, 2013; Pupo \& Ayres, 2013). A multiplicidade de cenários acena para o fato de que a busca por ajuda psicológica e por uma escuta qualificada em uma situação de urgência/ emergência não deva ocorrer notadamente em serviços tradicionais de Psicologia, mas que podem estar em locais que não possuem o saber psicológico como norteador do serviço prestado à comunidade. É o caso de comunidades religiosas, responsáveis pela oferta de ensinamentos, possibilitadoras de experiências espirituais de acordo com cada crença e também de auxílio e orientação para diferentes situações de vida (Scorsolini-Comin, 2014).

No caso específico dos terreiros de umbanda, também conhecidos popularmente como centros espíritas, a busca por apoio ocorre também em função das características dos atendimentos espirituais oferecidos à população em geral. A umbanda é uma religião de origem africana que recebeu influências do catolicismo, do espiritismo kardecista e de elementos de raízes indígenas, sendo considerada uma religião "à moda brasileira" (Silva, 2005, p. 99) surgida nas décadas de 1920 e 1930 no Rio de Janeiro. Oferece um cenário no qual a escuta acerca dos problemas experienciados ao longo da vida é suportada por uma atitude de respeito ao sagrado e de oferta de ajuda ao outro em sofrimento (Bairrão, 2005), sendo que as chamadas consultas fazem parte do ritual religioso. Essa oferta de ajuda ocorre por parte dos espíritos ou entidades que são incorporados pelos médiuns de cada terreiro. Embora cada terreiro mantenha uma organização própria (entidades ou espíritos recebidos no terreiro por meio do transe de possessão, rituais, dias de funcionamento) e um protocolo de atendimento (que envolve a quantidade de pessoas que cada médium pode atender, a duração de cada encontro/consulta, entre outros aspectos práticos), geralmente ocorrem atendimentos abertos à população nos quais os médiuns incorporam espíritos/entidades conhecidos como pretos-velhos, caboclos, baianos, marinheiros, exus e pombagiras. Para um maior aprofundamento na compreensão da umbanda e seus elementos, recomenda-se a leitura de uma vasta literatura científica na área (Dias \& Bairrão, 2011; Macedo \& Bairrão, 2011; Negrão, 1996; Silva, 2005).

As consultas espirituais geralmente são organizadas a partir da demanda específica trazida por cada consulente, sendo que diversas são as queixas relatadas nos terreiros, como problemas profissionais, conjugais, de relacionamentos, de educação e criação dos filhos, bem como pedidos de curas e proteção. Mas nem sempre as pessoas apresentam uma queixa nessas consultas, podendo haver o pedido por um passe ou uma bênção, limpeza espiritual, desenvolvimento mediúnico, entre outros. Desse modo, pode-se compreender que o terreiro de umbanda também funciona como uma instituição de ajuda que acolhe diferentes demandas e pessoas em busca de auxílio e orientação para o enfrentamento de problemáticas de diferentes ordens (Costa-Rosa, 2008). Há que se considerar, no entanto, que embora a umbanda esteja alicerçada na caridade, há outros elementos que caracterizam essa religião, como 
o culto às entidades (orixás e santos), a realização de festas voltadas a esses espíritos (como o Dia de São Cosme e Damião), o desenvolvimento mediúnico de pessoas que desejam se tornar médiuns, entre outros.

Embora exista literatura sobre as aproximações e distanciamentos entre o aconselhamento psicológico e o aconselhamento espiritual (Alves \& Seminotti, 2009; Scorsolini-Comin \& Santos, 2013), não são encontrados registros de atendimentos de urgência na modalidade de plantão que tenham o terreiro como cenário de desenvolvimento, aplicação e pesquisa. A aproximação da prática do plantão psicológico ao contexto umbandista ocorreu a partir de atividades de pesquisa desenvolvidas pelo autor em um terreiro localizado no interior do Estado de São Paulo desde o ano de 2012. Nesse sentido, o presente estudo objetiva apresentar e discutir a implantação de um serviço de plantão psicológico em uma comunidade religiosa umbandista, buscando compreender o contexto de criação desse serviço, suas características, demandas, dificuldades e possibilidade de atenção à comunidade.

\section{Método}

\section{Tipo de Estudo}

Trata-se de um estudo de caso coletivo a partir de uma experiência ocorrida em uma comunidade religiosa. Os casos individuais apresentados permitem que se possa compreender de modo mais particular o fenômeno investigado, aqui especificamente o plantão psicológico. Uma preocupação do presente estudo é que o mesmo não funcione como o retrato de uma experiência particular, mas justamente possa subsidiar reflexões mais amplas no campo do plantão e do aconselhamento psicológico, sendo de interesse de pesquisadores e profissionais que atuam neste contexto. A escolha dos casos apresentados nas vinhetas partiu da representatividade desses atendimentos para a compreensão do serviço de plantão psicológico neste contexto e do processo que envolve desde a recepção da pessoa até o encaminhamento ou desfecho do caso. O critério de potencial de formação foi seguido como forma de dialogar com outros estudos e experiências a fim de contribuir com a atuação em contextos semelhantes (Alves-Mazzotti, 2006; Stake, 2000).

\section{Procedimento}

Coleta de Dados. A partir da explicitação detalhada de como o serviço tem se organizado, serão apresentadas duas vinhetas clínicas de atendimentos já realizados na modalidade de plantão. Essas vinhetas referem-se a atendimentos realizados nos anos de 2013 e 2014 e retratam a implantação do serviço na comunidade. Trata-se de relatos com nomes fictícios, a fim de resguardar o cuidado ético com os participantes. Foram omitidos alguns detalhes que poderiam, porventura, identificar os colaboradores. Tais vinhetas são ilustrativas das demandas atendidas e dos encaminhamentos realizados no contexto do plantão. Essas vinhetas foram construídas a partir de relatos em diários de campo realizados pelos plantonistas, escritos logo após cada atendimento e armazenados em banco de dados. As vinhetas foram escritas sumarizando os pontos principais de cada caso tendo em vista o objetivo do presente estudo.

Análise dos Dados. Após a apresentação das vinhetas, estas foram analisadas a partir da abordagem centrada na pessoa e pela literatura científica produzida acerca da etnopsicologia (Leal de Barros \& Bairrão, 2010; Macedo, Bairrão, Mestriner, \& Mestriner, 2011; Pagliuso \& Bairrão, 2011), que oferece suporte ao contexto no qual foi desenvolvida a intervenção aqui relatada. A etnopsicologia investiga a maneira como variados grupos étnicos administram conflitos, vivenciam as emoções e os relacionamentos interpessoais, com destaque para as terminologias, sistema de compreensão do outro, processos conceituais e interativos existentes em cada comunidade e que são empregados na construção de significados sociais da vida cotidiana (Pagliuso \& Bairrão, 2011; White \& Kirkpatrick, 1985). Assim, oferece subsídios para intervenções em contextos sociais, tendo como princípios o respeito pelo outro, suas crenças e visões de mundo.

A abordagem centrada na pessoa (Rogers, 1974, 2001) foi empregada no delineamento dessa proposta e nos atendimentos realizados. Entre as principais ideias subjacentes a essa abordagem está a concepção de ser humano inte- 
gral e que caminha no sentido de sua autorrealização. Essa autorrealização se refere à tendência ao crescimento experiementada por todas as pessoas, de modo que o psicólogo deve se colocar como um facilitador do processo de autodescoberta, de tomada de consciência e de busca pela mudança. Rogers (1974) destaca, nesta abordagem, as atitudes básicas que devem ser desenvolvidas pelo psicólogo ao entrar em contato com a pessoa que busca ajuda: (a) congruência ou autenticidade, que se refere ao fato de o psicólogo tentar, ao máximo, ser ele mesmo naquela situação, pensando sobre os relatos a partir de seu mundo, seus valores, ou seja, considerando seu universo de sentimentos e práticas para que possa se colocar à disposição de uma pessoa em sofrimento; (b) consideração positiva pelo outro, que envolve a aceitação de uma pessoa em sofrimento sem atitudes de pré-julgamento ou de valoração sobre os comportamentos da pessoa que busca ajuda; (c) postura empática, que se refere ao fato de o profissional tentar, ao máximo, colocar-se no lugar do outro, não julgando suas atitudes e comportamentos, mas acompanhando-o ao longo do processo de crescimento pessoal, compartilhando sentimentos, experiências e escolhas. Essas três atitudes básicas, em linhas gerais, seriam responsáveis pela eficácia nos atendimentos, pois mostrariam à pessoa que busca ajuda a possibilidade de receber apoio de uma pessoa concreta, capaz de compreender o sofrimento de outro e se colocar à disposição para ouvi-la, compreendê-la e ajudá-la ou, simplesmente, de estar genuinamente com ela por meio de sua presença autêntica.

\section{Considerações Éticas}

O projeto que deu origem a este estudo foi aprovado pelo Comitê de Ética em Pesquisa da instituição de ensino de origem do autor (Protocolo 2164/2012).

\section{Resultados}

\section{Descrição do Serviço}

O plantão psicológico foi desenvolvido em uma comunidade religiosa umbandista, na região periférica de uma cidade de médio porte no inte- rior do Estado de São Paulo. Esta comunidade é centralizada em um terreiro existente há mais de dez anos e que congrega cerca de 20 médiuns e 20 cambonos (ajudantes dos médiuns nos rituais e nos atendimentos ao público). Este terreiro é coordenado por uma equipe de médiuns e colaboradores, tendo na figura do pai de santo o seu representante espiritual oficial e de maior respeito na hierarquia. Este pai de santo atua como médium há mais de 40 anos, tendo 67 anos de idade, viúvo, pai de três filhos, com baixa escolaridade e aposentado. Construiu o terreiro em um vilarejo em que várias pessoas de sua família residem, inclusive ele. Desse modo, o terreiro se localiza em sua própria residência, em uma espécie de garagem estendida, sendo ladeado por casas em que vivem seus parentes e filhos. $\mathrm{O}$ terreiro funciona duas vezes por semana. Às segundas-feiras à noite há as giras de pretos-velhos, símbolos de bondade e moralidade, considerados espíritos calmos, meigos, humildes e paternais, que acolhem e apaziguam os consulentes (Dias \& Bairrão, 2011). Às sextas-feiras ocorre o atendimento ao público a partir das giras de espíritos de caboclos, baianos e, uma vez ao mês, a chamada "virada de banda", consagrada a exus e pombagiras (Macedo \& Bairrão, 2011). Em cada dia de funcionamento são atendidas cerca de 80 pessoas não apenas da comunidade próxima ao terreiro, mas de diferentes regiões da cidade. As reuniões públicas são abertas pontualmente às 20 horas e encerradas por volta das 23 horas. Cada médium atende uma média de sete pessoas nesse período, sendo que cada atendimento é realizado em cerca de 20 minutos.

As intervenções psicológicas na modalidade de plantão foram realizadas por dois psicólogos que desenvolvem pesquisas nessa comunidade religiosa há mais de dois anos, com estudos sobre mediunidade, práticas de saúde e interpretação nas consultas espirituais. $\mathrm{O}$ pedido pelos atendimentos psicológicos ocorreu de duas formas: (a) espontaneamente, por pessoas da comunidade e por médiuns que sabiam que os pesquisadores eram psicólogos; (b) por indicação do chefe do terreiro, o pai de santo, que recebe diariamente várias pessoas em busca de ajuda, conselhos e de atendimentos espirituais. O pai 
de santo, neste contexto, funcionou como um grande incentivador do trabalho dos psicólogos, tanto oferecendo uma sala reservada do terreiro para os atendimentos como divulgando o serviço na comunidade, na medida em que as pessoas buscavam o seu auxílio. Em suas palavras, ele reconhecia no pedido de ajuda de muitas pessoas a possibilidade de que os psicólogos pudessem intervir em casos que não eram considerados por ele como demandas espirituais. Assim, os encaminhamentos eram realizados em situações nas quais o pai de santo identificava que as pessoas precisavam ser ouvidas, acolhidas e receber suporte profissional, não necessitando de apoio espiritual, como orientações quanto a trabalhos espirituais, banhos, rezas ou outros procedimentos. Tendo em vista essas demandas e considerando a disponibilidade para os atendimentos, os psicólogos se organizaram para atender as pessoas que assim o desejassem no mesmo período em que o terreiro estava aberto ao público.

O serviço de plantão foi estruturado da seguinte forma: às sextas-feiras, quando o terreiro é aberto à comunidade das 20 às 23 horas, um dos psicólogos ficava à disposição da comunidade para esses atendimentos. Os atendimentos não eram agendados, mas era informado aos interessados que haveria um profissional com o qual poderiam conversar no período de funcionamento do terreiro. Assim, as pessoas passaram a procurar espontaneamente os atendimentos em plantão. Esses atendimentos ocorriam, desse modo, nos mesmos dias e horários em que os "trabalhos" do terreiro, ou seja, enquanto os médiuns atendiam aos consulentes da comunidade. $\mathrm{Na}$ maioria das vezes, as pessoas que buscavam o plantão também procuravam, na mesma ocasião, o atendimento com algum médium. Assim, os atendimentos em plantão ocorriam antes ou depois de o consulente ser atendido por um médium. Como os atendimentos com os médiuns são organizados por meio de fichas distribuídas à comunidade por ordem de chegada, os profissionais atuantes no plantão se estruturavam para que os atendimentos psicológicos não se sobrepusessem às conversas com os médiuns incorporados. Essa estruturação do serviço de atendimento psicológico a partir da demanda da comunidade e das características da instituição (terreiro) revela um dos aspectos mais importantes dessa intervenção, que é justamente a coexistência de dois serviços de atenção à comunidade que guardam diferenças em relação à sua organização, objetivos e singularidades, mas que conservam um aspecto central: a ajuda oferecida à pessoa em busca de atendimento ou de orientação.

\section{Vinheta 1}

Janaína (nome fictício) buscou o atendimento por indicação de seu filho, que é médium. Ela já foi médium, mas teve que se afastar por um problema de saúde. Logo nas primeiras falas, mostrou-se bastante emocionada ao contar sobre a sua família e começou a chorar. Neste primeiro atendimento, a sua maior dificuldade era em relação à filha. Disse que precisava de ajuda por conta desta, que era muito nervosa e que havia agredido Janaína na semana anterior. A filha havia brigado com o namorado por ciúme e ela se aproximou e tentou contê-la. Como isso não ocorreu, a filha bateu na mãe. Contou como era o clima em sua casa, marcado por muitas brigas e discussões frequentes. O psicólogo destacou a importância de que ela também fosse atendida, pois se preocupava demais com os filhos e precisava de um espaço para que pensasse a respeito da sua própria vida, para que pudesse se acalmar também. Ela chorou por diversas vezes ao longo da conversa. A mãe estava muito preocupada com a filha, pedindo que o psicólogo a atendesse também. Janaína ficou mais tranquila após o atendimento, retornando mais tarde com a filha, Joana.

A jovem foi ao atendimento à noite, conforme combinado, juntamente com a mãe e o namorado. Assim que chegaram, o namorado já afirmou que ela era uma pessoa muito nervosa. Afirmou que não sabia por que estava ali, que a mãe apenas tinha dito que ela seria atendida no terreiro. Perguntou ao plantonista se ele era médium, ao que respondeu que era psicólogo e prestava atendimento à comunidade do terreiro. Ela pareceu assustada em um primeiro momento, mas depois ficou à vontade. Ao longo do atendimento, revelava ser um pouco dispersa ou pensativa, por vezes ficou em silêncio, parecia que não sabia o que dizer. Disse que não havia se pre- 
parado para conversar. Contou que trabalhava, tinha parado de estudar, era uma pessoa muito nervosa, gostava de falar e era agressiva. Estava namorando, mas teve relacionamentos amorosos anteriores bastante conturbados, inclusive com histórico de violência física. Contou que por qualquer coisa ela apanhava e que aprendeu a ser "grossa". O plantonista disse que quando as pessoas se agridem há um mal-estar que atinge toda a família, não apenas o casal que está brigando. Conversaram sobre como é difícil se controlar diante de uma situação de estresse. Ela disse que não se controlou ao dar um tapa na mãe, que foi a sua primeira reação. O psicólogo comentou que era importante ela se acalmar diante dessas situações, que o mais forte é aquele que se segura, que tenta se acalmar e conversar. Joana assumiu a culpa pela briga e pela agressão à mãe e concluiu que uma forma de resolver a situação seria conversar com a mãe e o irmão, mas não pediria desculpas, pois a situação já havia passado. $\mathrm{O}$ plantonista destacou que essa conversa poderia aproximá-la de sua família e perguntou se ela tinha vontade de resolver essa situação. Joana respondeu afirmativamente e embora receasse que essa conversa pudesse culminar em uma nova briga, disse que tentaria o apaziguamento. O plantonista explicou que se ela fosse conversar com eles não era uma garantia de que as coisas iriam se esclarecer e resolver. Também não era possível garantir que não haveria uma nova briga. Mas a conversa poderia ser um primeiro passo no sentido de aproximar mais de familiares e valorizá-los. Destacou-se que o pedido de ajuda partiu da mãe, de modo que isso poderia significar a sua preocupação com Joana. Ela concordou e disse que não tinha pensado nisso. Simulou com o plantonista o que diria para a mãe.

Então o plantonista perguntou o que ela mais valorizava em sua vida, ao que respondeu: ser feliz, trabalhar e a família. O plantonista perguntou como ela estaria cuidando dessa família, já que ela valoriza tanto essa dimensão. Ela primeiro disse que estava tudo normal, mas depois disse que as coisas poderiam melhorar. Evidenciou-se que ela era uma pessoa trabalhadora, com saúde, bonita e com recursos, de modo que poderia ter outra atitude diante da mãe e do irmão, ao que ela concordou. O plantonista, ao notar que Joana estava falando pouco, disse que ela podia confiar nele e naquele espaço, que havia a questão do sigilo e o que ela dissesse ficaria ali entre eles, mesmo atendendo outras pessoas da sua família. Ela disse que da próxima vez estaria mais à vontade, pois iria para casa e pensaria no assunto após a conversa. Aventou-se a possibilidade de chamar a mãe naquele momento para que pudessem conversar, mas Joana preferiu que essa conversa ocorresse em casa. Ao final do atendimento, o plantonista destacou a possibilidade de que Joana retornasse na semana seguinte, caso desejasse. O plantonista sentiu que Joana tinha ficado mais calma e, que, de alguma forma, ela tinha pensado um pouco sobre o que aconteceu. Joana não retornou ao atendimento na semana seguinte, mas a sua mãe sim. Disse que a situação tinha melhorado, não haviam brigado mais.

Neste segundo atendimento, ocorrido às vésperas de Natal, Janaína comentou sobre sua família e demonstrou estar sofrendo bastante. Chorou em dois momentos quando dizia que sentia saudades do pai, já falecido, e que era ela que tinha que cuidar da sua mãe, que estava adoecida. Foi uma sessão na qual o psicólogo quase não conseguiu falar. Todas as intervenções verbais eram interrompidas por falas de Janaína, que mostrava que a sua situação era muito complexa, por vezes afirmando que o plantonista "não estava entendendo o que ela estava dizendo". Em certa altura, o psicólogo perguntou se ela poderia ver algo positivo naquelas suas vivências, pois se só havia coisas ruins e ela não via nenhuma saída para enfrentar a situação, seria muito difícil dizer qualquer coisa. Ela concordou com o plantonista. Em suas anotações acerca do atendimento, o psicólogo destacou, de início, a sua sensação de impotência diante da fala de Janaína, carregada de sentimentos e experiências dolorosas e de difícil resolução. Ao mesmo tempo, conseguia empatizar com ela e compreender seu sofrimento, embora tivesse dificuldade de explorar possíveis falas que a ajudassem naquele momento. Em um segundo momento, relatou a importância de estar ali e ouvir Janaína, considerando que a sua escuta poderia ser importante para ela naquele momento, ainda que ele não ti- 
vesse dito nada ou mostrado as suas observações sobre o caso. Janaína saiu do atendimento ainda emocionada, desejando um bom Natal ao plantonista. Uma repercussão a ser considerada foi que Janaína telefonou para o psicólogo no período da tarde e agradeceu pela conversa da manhã, afirmando que já estava colocando em prática o que o profissional havia falado para ela "na aula" daquele dia, que tudo "começava a se resolver". Destaca-se, aqui, a compreensão do atendimento psicológico como uma aula, mostrando a pouca familiaridade com um processo psicoterápico, bem como a atribuição das próprias falas de Janaína ao psicólogo. Assim, reconhece-se que a fonte de ajuda partiu da própria participante e de seus recursos, mobilizada pela presença genuína do psicólogo.

Neste caso, o entrelaçamento com a etnopsicologia pode ser observado a partir de do fato de o atendimento ter sido realizado na própria comunidade religiosa, sendo o terreiro identificado como um local no qual a família poderia ser acolhida de modo autêntico pelo profissional de Psicologia, no momento de urgência. Obviamente que esse apoio poderia ser oferecido por outro serviço ou em outra instituição, mas o terreiro foi um cenário privilegiado justamente pelo fato de a família frequentá-lo semanalmente, estar envolvida em suas atividades e associá-lo com a oferta de ajuda. A confiança depositada por Janaína neste espaço pode ser expandida para o plantão lá realizado. Janaína chegou ao plantão por sugestão do filho, que conhecia os atendimentos, revelando a transmissão da oferta de apoio psicológico naquele contexto.

\section{Vinheta 2}

Marilize possui cerca de 30 anos e frequenta o terreiro há bastante tempo, conhecendo a estrutura dos atendimentos e tendo proximidade com o pai de santo. Além das consultas regulares às segundas e sextas-feiras, sempre procura a ajuda do pai de santo em dias e horários diferentes de atendimento ao público para poder conversar sobre seus problemas. Em um desses encontros, o pai de santo afirmou que ela não tinha problemas espirituais, mas que precisava do acompanhamento de um psicólogo, devido aos conteúdos serem relativos, em sua maioria, ao campo do trabalho e de um relato de insatisfação profissional. Desse modo, fez uma espécie de "encaminhamento" ao dizer que ela poderia buscar atendimento ali mesmo no terreiro, na noite de sexta-feira, a cargo de um profissional, gratuitamente. Quando o psicólogo chegou ao terreiro foi recebido pelo pai de santo, que lhe mostrou Marilize. Depois do plantão, Marilize seria atendida por um médium do terreiro.

No primeiro encontro, estava bastante agitada por conta de um problema vivido em seu trabalho. Como funcionária pública, atuava em uma instituição há cerca de cinco anos, e já havia pedido transferência de área cinco vezes. Desse modo, quando chegou ao atendimento, estava em sua sexta área na mesma instituição. Tinha a sensação que todas as pessoas de seu emprego a perseguiam e queriam o seu mal. Revelou histórico de insatisfação no trabalho e de aborrecimentos constantes em função de acontecimentos de sua rotina profissional. Estava alarmada com um fato ocorrido no trabalho que havia despertado a desconfiança de todos em relação à sua atuação. A atitude do plantonista foi de acolhê-la e ajudá-la a clarificar a sua queixa, mostrando de que modo ela poderia se posicionar diante daquele conflito. Marilize mostrou-se uma pessoa rígida em relação às suas percepções, com pouca flexibilidade para olhar para a mesma situação de um modo novo. No segundo encontro, parecia bem diferente e contou como a situação que a afligia na semana passada havia se resolvido. Parecia se sentir menos perseguida, mas ainda mostrava a sua insatisfação em relação ao seu emprego e à área na qual estava atuando. Foi possível perceber que Marilize havia abandonado vários de seus planos de adolescência, revelando-se como uma pessoa insatisfeita com a sua vida, com o fato de não ter tido filhos e não ter se casado. Mostrou-se disponível para iniciar uma psicoterapia, reconhecendo que as suas atitudes estavam trazendo sofrimento para a sua vida. No terceiro atendimento, também realizado em esquema de plantão e sem prévio agendamento, reafirmou a necessidade de mudar. Destacou que havia feito um novo pedido de transferência de área, mas que também buscava outro empre- 
go a partir de um concurso que iria prestar. Ela passaria a se dedicar aos estudos em um curso preparatório para o concurso, motivo pelo qual disse que não mais procuraria o atendimento às sextas-feiras, já que o curso ocorria todas as noites ao longo da semana. O profissional destacou que o plantão ocorria sempre às sextas-feiras às 20 horas, mostrando a sua disponibilidade para atendê-la novamente quando ela sentisse necessidade. Marilize mostrou-se contente com a possibilidade e afirmou que procuraria o serviço se fosse necessário.

Após três semanas, retornou ao plantão trazendo queixas semelhantes aos demais encontros, afirmando que precisava de ajuda para mudar. No entanto, foi capaz de se emocionar e contar mais sobre a sua história, abordar aspectos de sua vida que poderiam estar relacionados ao que vinha experienciando na atualidade. Sempre que queria mudar algum aspecto de sua vida, anotava em sua agenda a palavra "mudança". No entanto, queixava-se de nunca conseguir promover sozinha essa mudança. Foi aventada a possibilidade de que ela começasse com atitudes pequenas que pudessem conduzir a uma mudança, como olhar mais para si e se conhecer melhor. Ela concordou com essa possibilidade e foi destacado que o próprio pedido de ajuda sinalizava para essa necessidade. Foi sugerido que ela fosse acompanhada em processo psicoterapêutico, a fim de que pudesse explorar mais a fundo esses aspectos. No entanto, a abertura do plantão foi reafirmada como uma possibilidade de escuta, embora seu caso pudesse ser melhor acompanhado em psicoterapia. Marilize aceitou ser acompanhada em psicoterapia e seguiu nesse processo a cargo do mesmo profissional.

\section{Discussão}

A partir das vinhetas apresentadas, algumas considerações podem ser tecidas. Um primeiro aspecto refere-se ao próprio surgimento do plantão psicológico neste contexto, profundamente influenciado por uma demanda reconhecida pelo pai de santo, um líder espiritual e uma pessoa de referência para as pessoas que ali frequentam. A sua sensibilidade para a demanda por atendi- mento psicológico pode emergir a partir do seu contato com a equipe de psicólogos e pesquisadores que frequentam o terreiro há mais de cinco anos, ou seja, o seu contato com os profissionais da Psicologia já é algo que faz parte de sua rotina. Participou de várias entrevistas e contribui com diversos estudos no campo da etnopsicologia, de modo que pode conversar em várias ocasiões sobre os atendimentos psicológicos, como eles eram organizados e como poderiam contribuir com o crescimento das pessoas.

Ao identificar uma demanda da comunidade, sugeriu aos psicólogos que esses atendimentos pudessem ser realizados naquele espaço, favorecendo que as pessoas se sentissem à vontade em um ambiente já conhecido por elas como de acolhimento e de resolução de problemas. Desse modo, mostrou-se uma figura central na estruturação e manutenção do serviço de plantão psicológico. Embora os plantonistas e alguns médiuns do terreiro divulguem esses atendimentos à comunidade, a maior parte dos encaminhamentos é feita pelo pai de santo a partir de uma escuta refinada que ocorre todos os dias em sua casa e no terreiro. Mostrou-se um divulgador do serviço e entusiasta da proposta, o que reforça a necessidade de que o plantão esteja alinhado ao serviço ao qual ele se vincula, o que permite um atendimento mais integrado à realidade das pessoas que ali frequentam.

\section{Plantão Etnopsicológico e Consultas Espirituais}

Outro aspecto que deve ser assinalado é a integração dos plantões à rotina de atendimentos espirituais com os médiuns, já que ocorrem no mesmo dia e horário. Desse modo, são serviços que funcionam paralelamente e que, como mostrado na segunda vinheta, as pessoas podem participar de ambos. Isso significa que as pessoas podem tanto se consultar com os médiuns incorporados e depois passarem pelo plantão e vice-versa. A atitude do plantonista deve ser a de acolhimento e não a de julgamento em relação à busca de atendimento espiritual ou às crenças manifestadas pelo cliente. É preciso sempre retomar a questão do contexto, de modo a compreender que se trata de uma instituição consagrada 
ao atendimento a pessoas em situação de dúvida, sofrimento e conflitos (Bairrão, 2005).

O plantonista deve se abrir à possibilidade de que o cliente expresse questões relacionadas à sua espiritualidade, à sua crença ou mesmo em relação a conselhos recebidos nos atendimentos com as entidades espirituais. Trata-se de elementos etnopsicológicos importantes que podem ser disparadores de reflexão no espaço do plantão e que podem compor os atendimentos, não devendo ser a atitude do psicólogo a de questionar as práticas religiosas existentes ou estabelecer um juízo de realidade, mas de pensar de que modo esses elementos (como a menção aos atendimentos com espíritos no plantão) podem ser significados na experiência de vida do cliente. Como esses elementos se relacionam com as suas experiências, promovendo modos de ser e de compreender os percursos de vida? O plantão neste contexto deve acolher esses elementos e integrá-los na compreensão do cliente, assim como destacado nos pressupostos do aconselhamento multicultural (Sehgal et al., 2011). Respeitar esse universo é um dos elementos que nos provocam à adoção da terminologia plantão etnopsicológico, justamente pelas especificidades desses atendimentos em comunidade religiosa.

Um dos expoentes da etnopsicanálise, Devereux (1977), ao trabalhar com culturas não ocidentais, destacava que os padrões para a construção do que é a normalidade seriam diferentes daqueles com os quais o profissional estaria acostumado. O indivíduo considerado normal seria aquele capaz de compreender e viver a cultura como um sistema que estrutura sua própria vida, suas maneiras de perceber e experienciar a realidade. A partir dessa consideração, Leal de Barros e Bairrão (2010), já no contexto brasileiro, afirmam que as disciplinas "etnopsis", entre elas a etnopsicologia, sugerem que os psicólogos não pensem a cultura como algo externo, mas como parte integrante da estrutura e da economia psíquica. Conhecer o indivíduo e suas redes de relações implica em considerá-lo em determinada cultura, como produto e como produtor dessa cultura. Isso corrobora as falas de Devereux (1977) no sentido de que os profissionais possuem a responsabilidade de conhecer de modo aprofundado a realidade na qual vivem os seus clientes.

No caso, o terreiro de umbanda e a comunidade religiosa formada a partir dele constituem importantes elementos a serem considerados pelos plantonistas nos atendimentos. Isso fica mais claro quando observamos a Vinheta 2, em que Marilize apresenta, por diversas vezes, falas que revelam suas crenças ou a cultura na qual está inserida, quando afirma que "há energias ruins sobre ela" ou quando destaca que uma determinada entidade disse que "ela irá mudar de emprego no fim do ano". Essas falas não podem ser compreendidas no plantão como um afastamento da realidade ou como uma não implicação de si no tratamento, mas justamente como orientações que possuem uma real repercussão no modo como ela organiza o seu pensamento e as suas ações no sentido de reverter a sua insatisfação com a vida e o trabalho. Também não deve haver sobreposição com as consultas dos médiuns. $\mathrm{O}$ chamado plantão etnopsicológico, desse modo, mostra não apenas o respeito por este contexto, mas também a utilização do mesmo como possibilidade de refletir, junto ao cliente, sobre as possibilidades de encaminhamentos após o plantão. Respeitar essas orientações como parte do processo de conhecimento é um elemento ensejado pelo fato dos plantões ocorrerem na própria comunidade. $\mathrm{O}$ conhecimento etnopsicológico, desse modo, destaca a necessidade de conhecer a fundo essa cultura, a fim de que as orientações oferecidas pelos profissionais de Psicologia possam se integrar a essa realidade e seus modos de vida (Leal de Barros \& Bairrão, 2010; Macedo et al., 2011).

\section{Vinhetas de um Serviço em Acontecimento}

Ambas as vinhetas são representativas do processo de aproximação entre plantonista e cliente para o estabelecimento de uma relação de confiança. Na primeira, a confiança já havia se estabelecido anteriormente, haja vista que Janaína já conhecia o plantonista, pois frequentava o terreiro em algumas situações e o mesmo psicólogo atendia o seu filho em psicoterapia. Assim, a busca por ajuda no plantão já se baseava em 
uma relação anterior. Na segunda vinheta o estabelecimento da confiança ocorreu aos poucos, pois Marilize, sobretudo no primeiro encontro, mostrava-se bastante perseguida em relação ao modo como ela percebia e criticava o seu trabalho, tendo a sensação de que supostamente o plantonista conhecesse as pessoas que faziam parte da sua situação dilemática. A explicitação de que se tratava de um ambiente sigiloso e profissional foi importante para que ela se sentisse mais à vontade, bem como a consideração de que o plantonista estava ali à sua disposição sem julgá-la, reforçando a atitude positiva e empática em relação ao outro (Rocha, 2013; Rogers, 2001).

Nas situações retratadas, pode-se observar que as mulheres atendidas estavam em sofrimento: Janaína por conta de sua família e da briga com a filha, Joana pelas agressões físicas que sofrera e pelas suas dificuldades de relacionamentos e Marilize por conta de seu trabalho. A clarificação da demanda apresentada por cada uma foi importante, mas observou-se que o acolhimento mostrou-se potencializador de uma atitude de abertura ao outro. Ao oferecer-se a presença genuína e uma escuta atenta, Janaína pode falar, explorar suas angústias, algo que ela não podia fazer em sua casa, pois era a referência de todos (família monoparental) e precisava ser "forte", o que equivale a dizer que não encontrava um espaço para si. O plantão a acolheu em um momento de maior mobilização emocional (véspera de Natal), sendo importante para que ela pudesse receber os parentes em sua casa. Como destacado por Amatuzzi (2008), a escuta é também uma modalidade de intervenção, facilitando que o outro tome uma posição no sentido de clarificar seus problemas. O que o plantonista havia relatado em seu diário como uma "impotência" diante do atendimento era, na verdade, a possibilidade de oferecer uma escuta autêntica (Mahfoud, 2013), pois revelava a sua preocupação com Janaína naquela situação. Tanto que o retorno sobre a repercussão positiva daquela escuta ocorrera horas mais tarde, com o telefonema da cliente.

Para Rogers e Wallen (2000, p. 11), o psicólogo deve "tornar possível ao cliente adqui- rir a libertação emocional em relação aos seus problemas e, como consequência, pensar mais claramente sobre si próprio e sobre a situação". Para tanto, as atitudes básicas de congruência, aceitação positiva incondicional e empatia tornam-se essenciais, pois permitem ao profissional estar genuinamente com aquele que busca ajuda. Assim, este profissional é um facilitador do processo de crescimento pessoal do cliente, estando junto com ele em seu processo de mudança, oferecendo suporte, aceitação, confiança e encorajamento para o desenvolvimento (Mahfoud, 2013). Como exemplificado na Vinheta 1 , o fato de Janaína ter sido ouvida em sua angústia, às vésperas dos festejos de Natal, pode clarificar não apenas a sua dor, mas os recursos que ela poderia potencializar para se reencontrar com sua família de origem. Como um espaço catártico ou de elaboração do vivido, o plantão proporcionou um espaço para aqueles sentimentos trazidos por Janaína. Além disso, a postura do plantonista de acolhimento e de escuta atenta forneceu indícios de que poderia manter-se confiante naquela relação.

$\mathrm{Na}$ Vinheta 2, o plantonista relatou dificuldades para empatizar com Marilize no primeiro encontro. Isso porque ela mostrava-se persecutória e, embora o profissional tentasse ajudá-la a clarificar o problema e desfazer a sensação de estar sendo perseguida, ela mostrava-se rígida a esse tipo de intervenção. No segundo encontro, no entanto, estando mais calma e com a situação dilemática outrora relatada aparentemente resolvida, puderam conversar sobre demais aspectos de sua insatisfação, possibilitando que o profissional conhecesse mais a sua história e a sua própria insatisfação, não ligada exclusivamente ao contexto de trabalho. Ainda que de modo tímido, o segundo encontro mostrava uma ressonância do primeiro atendimento, sendo que Marilize se reportava a alguns aspectos levantados pelo plantonista no primeiro encontro. Mesmo com as dificuldades relatadas pelo plantonista, é importante assinalar que houve uma atitude positiva em relação ao outro (Rogers, 2001), compreendida na abordagem centrada na pessoa como atenção, afeição, interesse e respeito pelo outro e sua história. 
Mesmo com a dificuldade de explorar a falta de flexibilidade da cliente e seu apego ao passado e aos comportamentos que desencadearam sofrimento, o plantonista mostrou interesse em conhecer a sua experiência, embora tenha sido complexo ouvi-la despojando-se de uma atitude avaliativa: "poderei libertá-lo do receio de ser julgado pelos outros?" (Rogers, 2001, p. 58). Para este autor, apesar de ser complexo emitir um olhar não avaliativo, é fundamental que o profissional se esforce para que os juízos de valor sejam emitidos pelo próprio cliente. Mas, retomando a primeira atitude básica anunciada por Rogers, a de autenticidade ou congruência do profissional, é fundamental que este consiga atuar, apesar de possuir em si julgamentos, valores e crenças. O importante é saber despojar-se dos mesmos e estabelecer uma relação que ajude o cliente em seu processo de crescimento pessoal (Rogers, 1974).

A constante abertura do serviço, possibilitando que as pessoas recorram a ele caso necessitem outras vezes, é uma característica, também presente em outras propostas (Fujisaka et al., 2013), que contribuem para a caracterização do serviço como auxílio em situações de urgência/ emergência. Isso é expresso quando Marilize volta a procurar o plantão depois de três semanas. Esse quarto encontro foi decisivo na tomada de sua decisão pela busca da psicoterapia. Pode-se considerar que o espaço do plantão permitiu que ela voltasse não apenas para relatar o seu sofrimento naquele momento, mas para anunciar, depois daquele tempo de distanciamento, que precisava mesmo de um atendimento mais intensivo, que seria proporcionado na psicoterapia. O tempo decorrido entre os plantões pode ter auxiliado a sua tomada de decisão e a clarificação da sua demanda, de modo a hipotetizarmos que o plantão possui também uma ressonância para "depois" do encontro.

\section{Formação do Plantonista no Contexto Etnopsicológico}

Decorrente desse aspecto, a formação do plantonista deve ser destacada. Embora o serviço atualmente conte com dois psicólogos e pesquisadores, com pós-graduação e que atuam como docentes universitários, abre-se a possibilidade de receber estudantes de graduação interessados nesses atendimentos e na formação específica no plantão etnopsicológico. Alguns apontamentos podem ser importantes para se pensar esse processo de formação. Primeiramente, faz-se necessário que o plantonista conheça os pressupostos técnicos do plantão psicológico e seja acompanhado em supervisão por um profissional com experiência na área (Paparelli \& Nogueira-Martins, 2007; Rocha, 2013). Em segundo lugar e fundamental para os atendimentos nesse contexto, é que o plantonista possa conhecer a fundo a cultura do local. Esse conhecimento pode se dar de diferentes modos, como frequentar o terreiro nos dias de atendimento à comunidade e também em horários diferentes, a fim de conhecer como as pessoas se relacionam naquele lugar, ou seja, conhecer seus modos de vida, hábitos, pessoas de referência na comunidade, entre outros aspectos. $\mathrm{Na}$ experiência em apreço, os psicólogos também atuam como pesquisadores na comunidade. Embora essa imersão seja uma importante experiência para os atendimentos, não há indicações, até o momento, de que o plantonista deva também ser um pesquisador ou frequentador da comunidade, que ocupe funções no terreiro (como a de cambono), mas que conheça esse universo, a população atendida, o modo como as consultas são realizadas, os rituais, as características da umbanda, entre outros elementos. A "imersão" na comunidade é importante para o treino do olhar e da escuta do plantonista, de modo que possa aproximar-se daquele universo, evitando posicionamentos etnocêntricos e estando atento à alteridade e ao contato com o outro (Devereux, 1977; Leal de Barros \& Bairrão, 2010). Os plantonistas em atuação neste terreiro possuem uma vasta experiência na comunidade, já realizaram diversos estudos nesse cenário, entrevistaram seus principais personagens e tornaram-se, ao longo do tempo, pessoas consideradas da própria comunidade, ainda que não residam naquela região e não a frequentem todos os dias.

Obviamente que essa imersão requer treino, disponibilidade interna e tempo. Esse tempo não pode ser mensurado, mas pode-se afirmar, neste estudo, que foi o tempo de imersão que esses 
psicólogos construíram junto à comunidade que abriu caminho para a criação do serviço de plantão, para o seu reconhecimento e fortalecimento. Isso aponta para a necessidade de considerar que a formação do plantonista não ocorre de modo súbito, mas é construída a partir do desenvolvimento de outras competências e habilidades, inclusive de atitudes que favoreçam o estabelecimento de uma boa relação de ajuda (Rogers, 2001). Esse parece ser um desafio das intervenções psicológicas em instituições, haja vista que não é preciso dominar apenas a técnica, mas também conhecer as práticas culturais do local e da comunidade a qual pretende se ofertar apoio profissional (Scorsolini-Comin, 2014).

Empatizar-se com o outro, reconhecendo a sua experiência e podendo compartilhar esse momento de sofrimento e de necessidade de ajuda encontra ressonância em um dos pressupostos da etnopsicologia, segundo o qual a ciência psicológica não deve fazer uso de um conhecimento "padronizado permeado por valores unívocos em detrimento do saber do outro" (Pagliuso \& Bairrão, 2011, p. 48). Ao dialogar com outras formas de produção de conhecimento e saberes construídos social, histórica e socialmente, pode-se compreender como é estar nessa comunidade, fazer parte dela, de modo a se apropriar do contexto conservando a capacidade crítica. Assim, destaca-se que é na capacidade de estar com o outro, de colocar-se em seu lugar e sustentar essa posição, que o plantonista sob a égide da etnopsicologia pode, de fato, compreender em seu universo de experiências, como é ser parte dessa comunidade e pensar sobre os valores ali construídos e reproduzidos.

A postura de empatia, fundamental no processo terapêutico e no estabelecimento de uma relação autêntica com o outro, segundo a abordagem centrada na pessoa (Rogers, 2001; Tassinari et al., 2013), pode ser construída a partir da imersão do plantonista na comunidade, o que foi relatado no presente estudo como um dos elementos que favoreceu a construção e a continuidade do plantão. É por essas características aqui discutidas que ousamos considerar a presente experiência como um autêntico registro de plantão etnopsicológico.

\section{Considerações Finais}

A partir do estudo de caso coletivo apresentado e da experiência de plantão psicológico desenvolvido em comunidade religiosa, alguns apontamentos podem ser iniciados, à guisa de conclusão. Em relação à diversificação de cenários de atuação, a proposta destaca a possibilidade de que psicólogos vislumbrem a oferta de apoio psicológico em contextos não tradicionais e, por que não, alinhados a outras práticas de orientação e de saúde, como no caso das consultas espirituais. Há que se considerar que o saber psicológico não constitui a única verdade e deve estar a serviço da população a partir do contato com outras práticas igualmente potencializadoras de bem-estar e de crescimento pessoal. No entanto, ainda não podemos destacar que a estruturação de um serviço de plantão psicológico poderia ocorrer em quaisquer comunidades religiosas, ou que os princípios adotados nesta experiência particular poderiam ser generalizados para outros contextos. O fato de se tratar de uma experiência voluntária, em uma comunidade religiosa na qual os atendimentos mediúnicos são orientados pelo princípio da caridade, pode ter contribuído para os resultados encontrados. Ainda assim, os elementos aqui discutidos podem ser aproximados de outras realidades e disparar novos olhares e intervenções.

Entre as limitações do plantão etnopsicológico, destaca-se que a imersão do plantonista no contexto de atenção psicológica constitui uma dificuldade que pode demandar tempo, haja vista que a proposta de atendimento psicológico na comunidade emergiu a partir de decorridos alguns anos da presença de psicólogos e grupos de pesquisa no terreiro que ilustra esta investigação. No entanto, mais do que uma dificuldade, é preciso assinalar que, cada vez mais, os profissionais de Psicologia devem estar abertos para essa forma de cuidado e atenção, o que sugere a necessidade de que tais conteúdos possam ser pesquisados, debatidos e refletidos no espaço universitário e no campo de estágio, a exemplo de outras experiências disponíveis na literatura científica (Paparelli \& Nogueira-Martins, 2007; Scorsolini-Comin, Souza, \& Santos, 2008; Zanuzzi et al., 
2014). A implantação do presente serviço não encontrou dificuldades significativas, mas pode-se destacar a necessidade de esclarecer à população atendida em que consiste uma intervenção psicológica e os elementos éticos desse cuidado. Aspectos como sigilo das informações e a escuta profissional tiveram que ser destacados e priorizados nos atendimentos, haja vista a pouca familiaridade das pessoas atendidas com a atuação do psicólogo. Outras especificidades referem-se ao manejo do tempo de cada atendimento e da organização do plantão de modo conjugado com as consultas mediúnicas, de modo que uma mesma pessoa pudesse, em um dia, ser atendida tanto pelo médium como pelo psicólogo.

Acreditamos no potencial dessa proposta no campo do aconselhamento multicultural (Sehgal et al., 2011) e as primeiras avaliações revelam que o serviço tem atingido o seu objetivo de oferecer apoio psicológico em situações de urgência/emergência. No entanto, os benefícios ou repercussões imediatas relatadas pelas pessoas atendidas não podem ser atribuídos exclusivamente ao plantão psicológico. Dialogar com os diferentes saberes e com a possibilidade de que as consultas com as entidades espirituais também promovam bem-estar e crescimento pessoal parece ser um importante reconhecimento dessa experiência. Atuar em uma comunidade religiosa parece ser uma oportunidade para abertura dos sentidos às diversas formas de ajuda que se encerram em um contexto no qual o apoio psicológico provém, na maioria das vezes, da escuta promovida por um médium ou um líder religioso da comunidade.

O plantão psicológico, desse modo, não pode ser oferecido com a intenção de se diferenciar do apoio já existente no terreiro, mas como uma prática paralela e integrada ao contexto religioso no qual as pessoas da comunidade estão imersas. Essa parece ser uma reinvenção (Fujisaka et al., 2013) no sentido de nos auxiliar a compreender a implantação do plantão psicológico em contextos diferenciados. Reconhecer esse diálogo integrador é uma das características do denominado plantão etnopsicológico, que deve ser alvo de mais pesquisas, a fim de consolidar um saber e uma prática no campo do aconselhamento psicológico.

\section{Referências}

Alves, M. C., \& Seminotti, N. (2009). Atenção à saúde em uma comunidade tradicional de terreiro. Revista de Saúde Pública, 43(Supl. 1), 85-91. doi:10.1590/S0034-89102009000800013

Alves-Mazzotti, A. J. (2006). Usos e abusos dos estudos de caso. Cadernos de Pesquisa, 36(129), 637651. doi:10.1590/S0100-15742006000300007

Amatuzzi, M. M. (2008). Por uma psicologia humana (2. ed.). Campinas, SP: Alínea.

Bairrão, J. F. M. H. (2005). A escuta participante como procedimento de pesquisa do sagrado enunciante. Estudos de Psicologia (Natal), 10(3), 441446. doi:10.1590/S1413-294X2005000300013

Cavalcanti Filho, J. P. (2013). Fernando Pessoa: $O$ livro das citações. Rio de Janeiro, RJ: Record.

Costa-Rosa, A. (2008). Práticas de cura místico-religiosas, psicoterapia e subjetividade contemporânea. Psicologia USP, 19(4), 561-590. doi:10.1590/S0103-65642008000400012

Devereux, G. (1977). Essais d'ethnopsyquiatrie génerale. Paris: Gallimard

Dias, R. N., \& Bairrão, J. F. M. H. (2011). Aquém e além do cativeiro dos conceitos: Perspectivas do preto-velho nos estudos afro-brasileiros. Memorandum, 20, 145-176.

Fujisaka, A. P., Breschigliari, J. O., Rocha, M. C., Eisenlohr, M. G. V., Kovács, M. J., \& Schmidt, M. L. S. (2013). Plantão psicológico em centro-escola: Tradição, reinvenção e rupturas. In M. A. Tassinari, A. P. S. Cordeiro, \& W. T. Durange (Eds.), Revisitando o plantão psicológico centrado na pessoa (pp. 211-228). Curitiba, PR: CRV.

Kovács, M. J. (2010). Sofrimento da equipe de saúde no contexto hospitalar: Cuidando do cuidador. Mundo Saúde, 34(4), 420-429.

Leal de Barros, M., \& Bairrão, J. F. M. H. (2010). Etnopsicanálise: Embasamento crítico sobre teoria e prática terapêutica. Revista da SPAGESP, 11(1), 45-54

Lessard, M.-J., Marchand, A., \& Lavoie, K. L. (2012). Interventions à l'urgence pour douleurs thoraciques non cardiaques avec ou sans anxiété de type panique. Canadian Psychology, 53(3), 178-191. doi:10.1037/a0027774

Macedo, A. C., \& Bairrão, J. F. M. H. (2011). Estrela que vem do Norte: Os baianos na umbanda de 
São Paulo. Paidéia (Ribeirão Preto), 21(49), 207216. doi:10.1590/S0103-863X2011000200008

Macedo, A. C., Bairrão, J. F. M. H., Mestriner, S. F., $\&$ Mestriner, W., Jr. (2011). Ao encontro do outro, a vertigem do eu: $\mathrm{O}$ etnopsicólogo em equipes de saúde indígena. Revista da SPAGESP, $12(2), 85-96$.

Mahfoud, M. (2013). Desafios sempre renovados: Plantão psicológico. In M. A. Tassinari, A. P. S. Cordeiro, \& W. T. Durange (Eds.), Revisitando o plantão psicológico centrado na pessoa (pp. 33-50). Curitiba, PR: CRV.

Negrão, L. (1996). Entre a cruz e a encruzilhada: Formação do campo umbandista em São Paulo. São Paulo, SP: Editora da Universidade de São Paulo.

Pagliuso, L., \& Bairrão, J. F. M. H. (2011). A etnopsicologia e o trabalho institucional em uma unidade de abrigo. Revista da SPAGESP, 12(1), 43-55.

Paparelli, R. B., \& Nogueira-Martins, M. C. F. (2007). Psicólogos em formação: Vivências e demandas em plantão psicológico. Psicologia: Ciência e Profissão, 27(1), 64-79. doi:10.1590/ S1414-98932007000100006

Perches, T. H. P., \& Cury, V. E. (2013). Plantão psicológico em hospital e o processo de mudança psicológica. Psicologia: Teoria e Pesquisa, 29(3), 313-320.

Pupo, L. R., \& Ayres, J. R. C. M. (2013). Contribuições e limites do uso da abordagem centrada na pessoa para a fundamentação teórica do aconselhamento em DST/Aids. Temas em Psicologia, 21(3), 1089-1106. doi:10.9788/TP2013.3-EE16PT

Rocha, M. C. (2013). Plantão psicológico em instituições de defesa de direitos. In M. A. Tassinari, A. P. S. Cordeiro, \& W. T. Durange (Eds.), Revisitando o plantão psicológico centrado na pessoa (pp. 211-228). Curitiba, PR: CRV.

Rogers, C. R. (1974). A terapia centrada no paciente. Lisboa, Portugal: Moraes.

Rogers, C. R. (2001). Tornar-se pessoa (4. ed.). São Paulo, SP: Martins Fontes.

Rogers, C. R., \& Wallen, J. L. (2000). Manual de counselling. Lisboa, Portugal: Encontro.

Rosenberg, R. L. (1987). Introdução: Biografia de um serviço. In R. L. Rosenberg (Ed.), Aconselhamento psicológico centrado na pessoa (pp. 1-13). São Paulo, SP: EPU.
Scorsolini-Comin, F., Souza, L. V., \& Santos, M. A. (2008). Tornar-se psicólogo: Experiência de estágio de Psico-oncologia em equipe multiprofissional de saúde. Revista Brasileira de Orientação Profissional, 9(2), 113-125.

Scorsolini-Comin, F., \& Santos, M. A. (2013). Counseling Psychology: A view of the scientific production in the Brazilian postgraduation. Revista Brasileira de Crescimento e Desenvolvimento Humano, 23(3), 338-345.

Scorsolini-Comin, F. (2014). Atenção psicológica e umbanda: Experiência de cuidado e acolhimento em saúde mental. Estudos e Pesquisas em Psicologia, 14(3), 773-794

Sehgal, R., Saules, K., Young, A., Grey, M. J., Gillem, A. R., \& Nabors, N. A. (2011). Practicing what we know: Multicultural counseling competence among clinical Psychology trainees and experienced multicultural psychologists. Cultural Diversity and Ethnic Minority Psychology, 17(1), 1-10. doi:10.1037/a0021667

Silva, V. G. (2005). Candomblé e umbanda: Caminhos da devoção brasileira. São Paulo, SP: Selo Negro.

Stake, R. E. (2000). Case studies. In N. K. Denzin \& Y. S. Lincoln (Eds.), Handbook of qualitative research ( $2^{\text {nd }}$ ed., pp. 134-164). Thousand Oaks, CA: Sage.

Tassinari, M. A., Cordeiro, A. P. S., \& Durange, W. T. (Eds.). (2013). Revisitando o plantão psicológico centrado na pessoa. Curitiba, PR: CRV.

White, G. M., \& Kirkpatrick, J. (Eds.). (1985). Person, self and experience: Exploring Pacific Ethnopsychologies. Berkeley, CA: The University of California Press.

Zanuzzi, T. R. L., Santeiro, T. V., \& Scorsolini-Comin, F. (2014). Estágio em NASF: Interlocuções entre psicoterapia breve, plantão psicológico e grupos operativos. In F. Scorsolini-Comin, L. V. Souza, \& S. M. Barroso (Eds.), Práticas em Psicologia: Saúde, família e comunidade (pp. 109-125). Uberaba, MG: Editora da Universidade Federal do Triângulo Mineiro. 